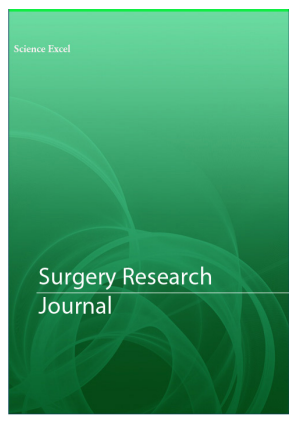

Correspondence

Adil Kbirou

Department of Urology, CHU IBN ROCHD, Morocco

- Received Date: 11 Sep 2021

- Accepted Date: 15 Sep 2021

- Publication Date: 25 Sep 2021

Copyright

(C) 2021 Science Excel. This is an openaccess article distributed under the terms of the Creative Commons Attribution 4.0 International license.

\title{
Revealing obstructive acute pyelonephritis of horseshoe kidneys, about 2 cases
}

\author{
Adil Kbirou*, Mahmoud Alafifi, Mohammed Dakir, Adil Debbagh, Rachid \\ Aboutaieb \\ Urology Department, Ibn Rochd Hospital, Casablanca 20250, Morocco
}

\begin{abstract}
Summary
The horseshoe kidney is a malformation of the upper urinary tract where the kidneys have a U-shape. This is most often the result of the fusion of the lower poles of both kidneys on the median plane. This congenital malformation can remain asymptomatic in $30 \%$ of cases and diagnosed incidentally during a radiological examination. The horseshoe kidney may increase the risk for occurrence of pyelonephritis or renal lithiases which may be accompanied by urinary tract dilation or vesicoureteral reflux (VUR). We reported two clinical cases consulting for a picture of obstructive pyelonephritic revealing horseshoe kidneys.
\end{abstract}

\section{Introduction}

The horseshoe kidney is a malformation most often asymptomatic, resulting from the fusion of the two kidneys, usually by their lower pole by fibrous or parenchymatous band. It is the most common renal fusion abnormality. Its incidence is estimated as $0.25 \%$ of the general population. It may be accompanied by some complications of pyelonephritis that require urgent management. Two young patients reported acute pyelonephritis in ER and by diagnosis, they revealed horseshoe kidneys cases.

\section{Clinical case 1}

Patient aged 27 years, with the emission of stones, consulted the emergency room for fever, lower back pain extends to the external genitalia for 4 days, associated with disorders of the lower urinary tract explained by urinalysis. The clinical examination showed a fever with a temperature of 40 degrees and left lumbar sensitivity. The complete blood count $(\mathrm{CBC})$ and blood smear showed hyperleukocytosis $28610 / \mathrm{microl}$ with the predominance of condensed chromatin neutrophils without thrombopenia, and for the level of the electrolyte: ultrasound showing acute kidney failure with 22.6 $\mathrm{mg} / \mathrm{l}$ Creatinine clearance (slightly high) and a high CRP at $251 \mathrm{mg} / \mathrm{l}$.

The reno-bladder ultrasound found a left pyelo-calyceal dilatation on probable coralliform calculation with TransCore content (Figure 1). Unpreping urinary tree $\mathrm{x}$-ray (AUSP) showed multiple calcium tone opacities shown at the left renal area (Figure 2).

The MRI objected to acute obstructive pyelonephritis and moderate hydronephrosis which are caused by multiple left nephrolithiasis associated with infiltration of perirenal fat and horseshoe kidneys. (Figure 3). Management included probabilistic antibiotic therapy based on 3rd generation as cephalosporins by the parenteral route and urinary bypass by a double J probe (Figure 4). observation exhibited clinical improvement with low back pain regression, normal body temperature, and biological improvement (Figure 5). Cytobacteriological examination of urine isolated a multi-sensitive Escherichia coli. The patient is scheduled to cure after a surgical procedure.

\section{Clinical case 2}

A 21-year-old patient, with no particular pathological history, consulted the emergency room for severe bilateral low back pain evolving for 7 days associated with disorders of the lower urinary tract with a urination burn. The clinical examination showed a high temperature estimated at 39.5 degrees and a right lumbar sensitivity without lumbar contact. The complete blood count showed hyperleukocytosis at $19000 /$ microl with the predominance of polynuclear neutrophils without thrombopenia and a high CRP at $182 \mathrm{mg} / \mathrm{l}$.

The reno-bladder ultrasound found moderate bilateral pyelocaliceal dilation which is larger on the right with finely 


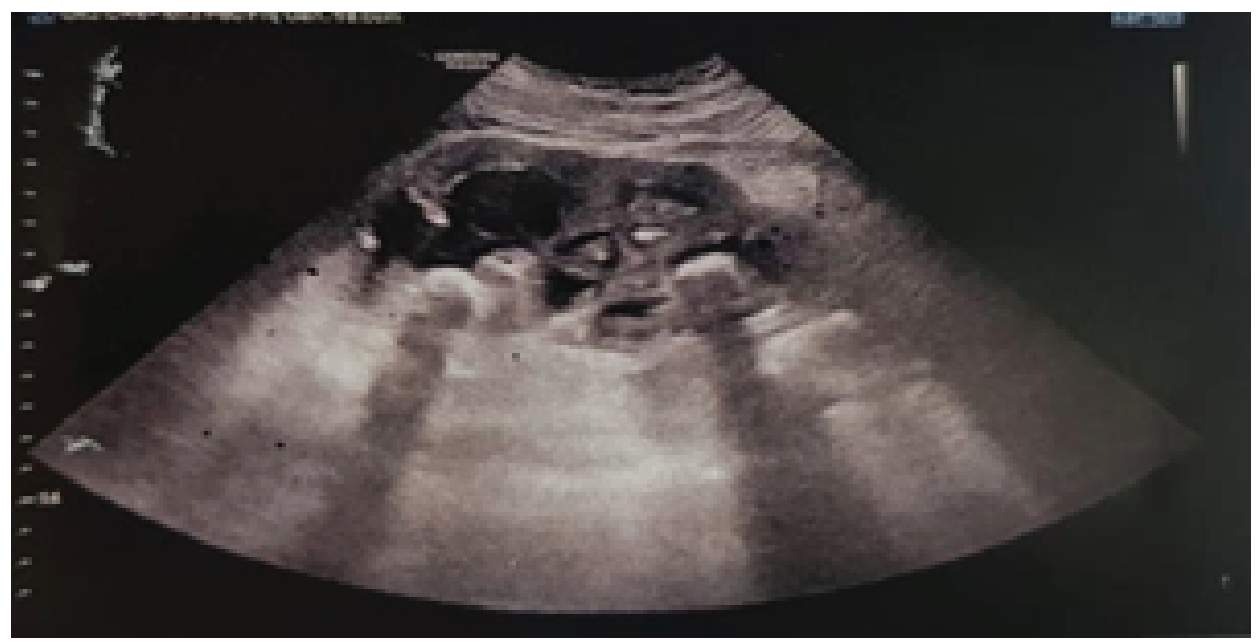

Figure 1. Reno-bladder ultrasound showing a left ureterohydronephrosis on probable coralliform lithiasis

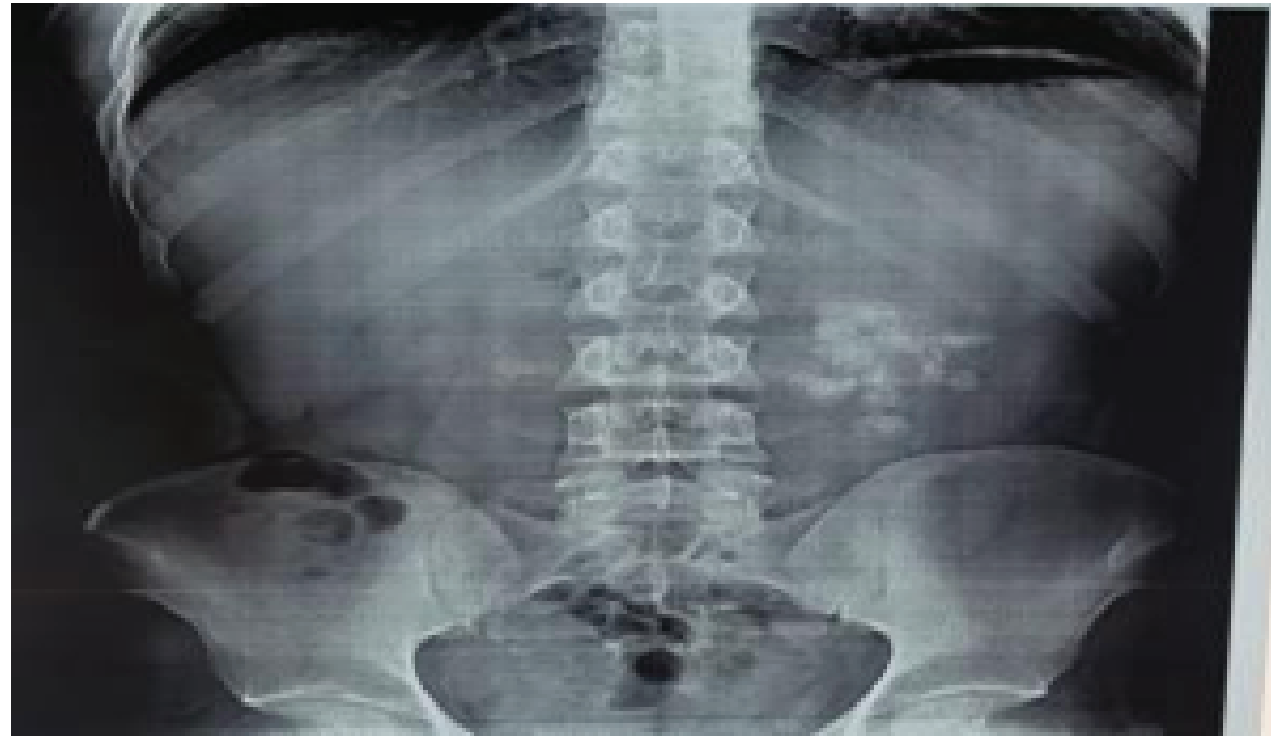

Figure 2. Reno-bladder ultrasound showing a left ureterohydronephrosis on probable coralliform lithiasis
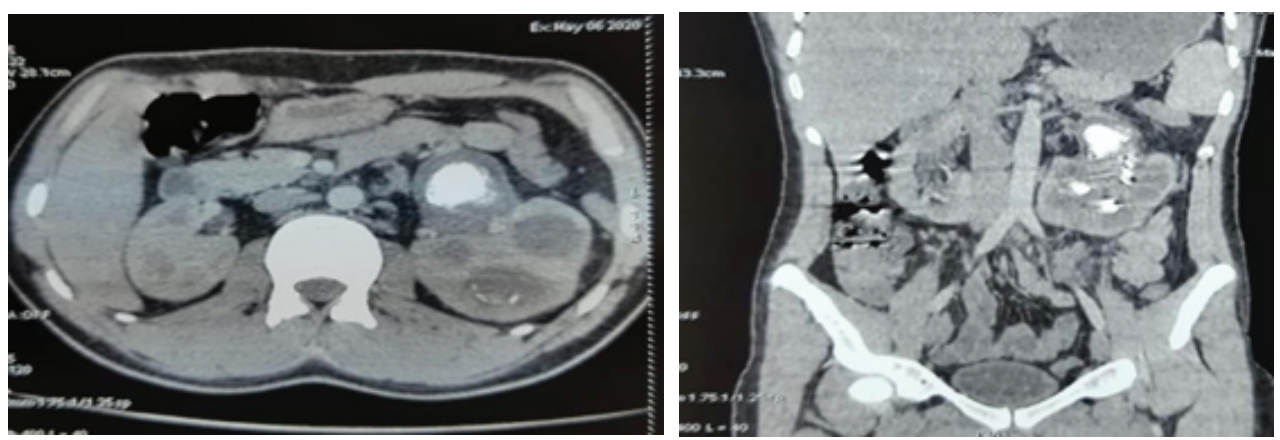

Figure 3. MRI showing acute obstructive pyelonephritis on horseshoe lithiasis kidneys 


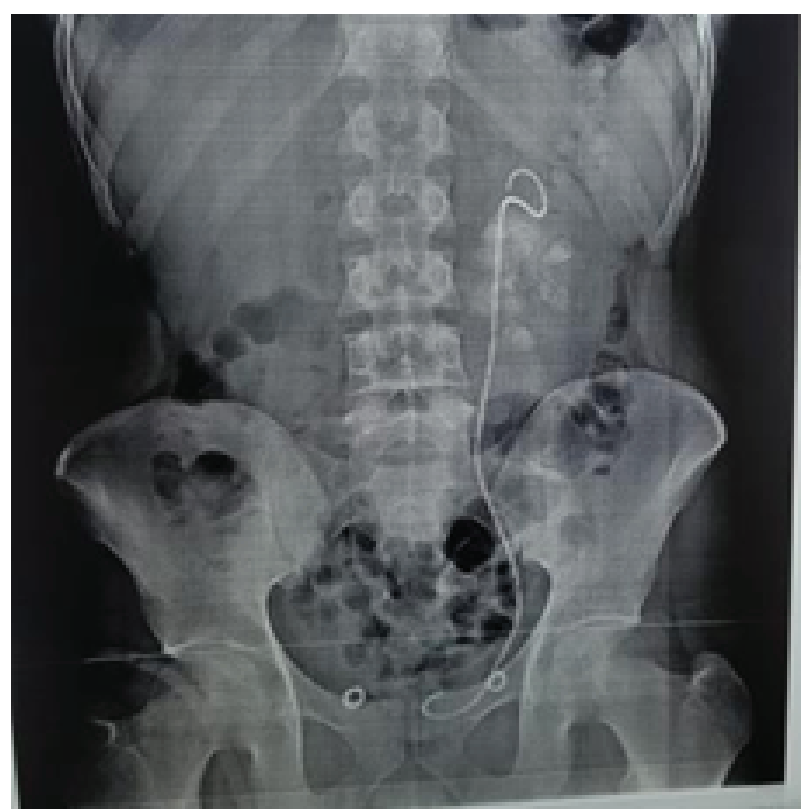

Figure 4. AUSP revealing bypass by double J probe

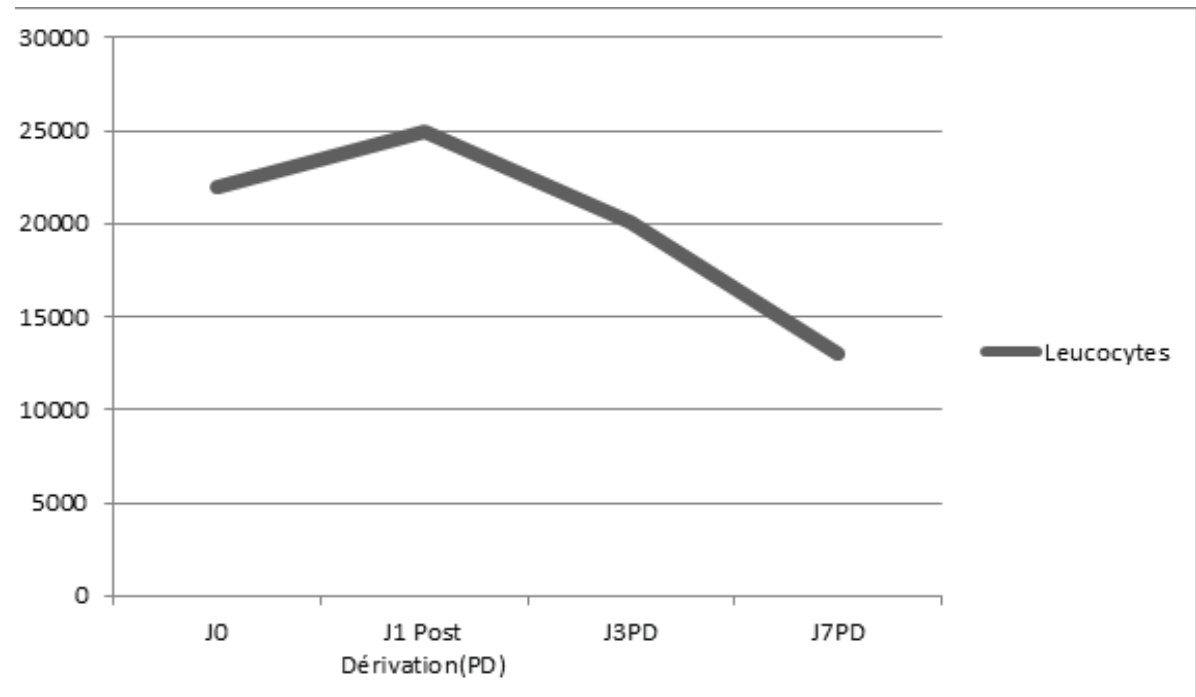

Figure 5. Evolutionary profile of leukocytes after urinary bypass
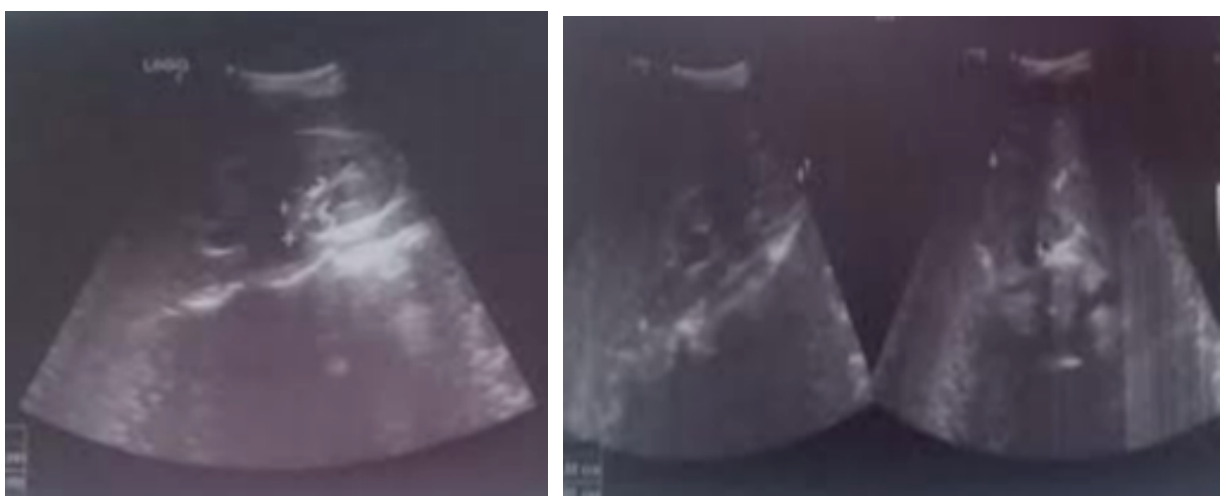

Figure 6. Reno-vesica ultrasound showing finely contented bilateral pyelolo-caliceal dilation echogenic. 

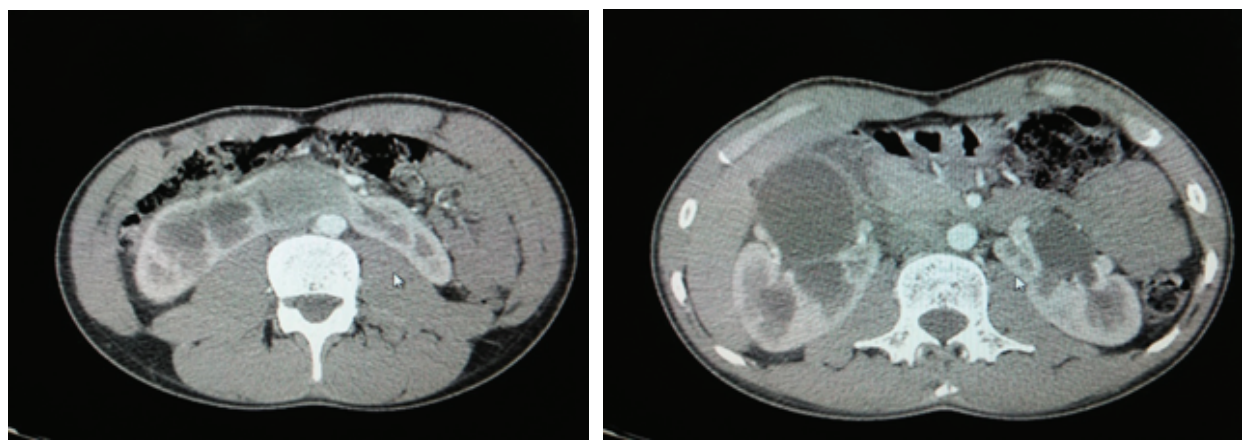

Figure 7. CT aspect in favor of horse-strapped kidney associated with pyelitis.

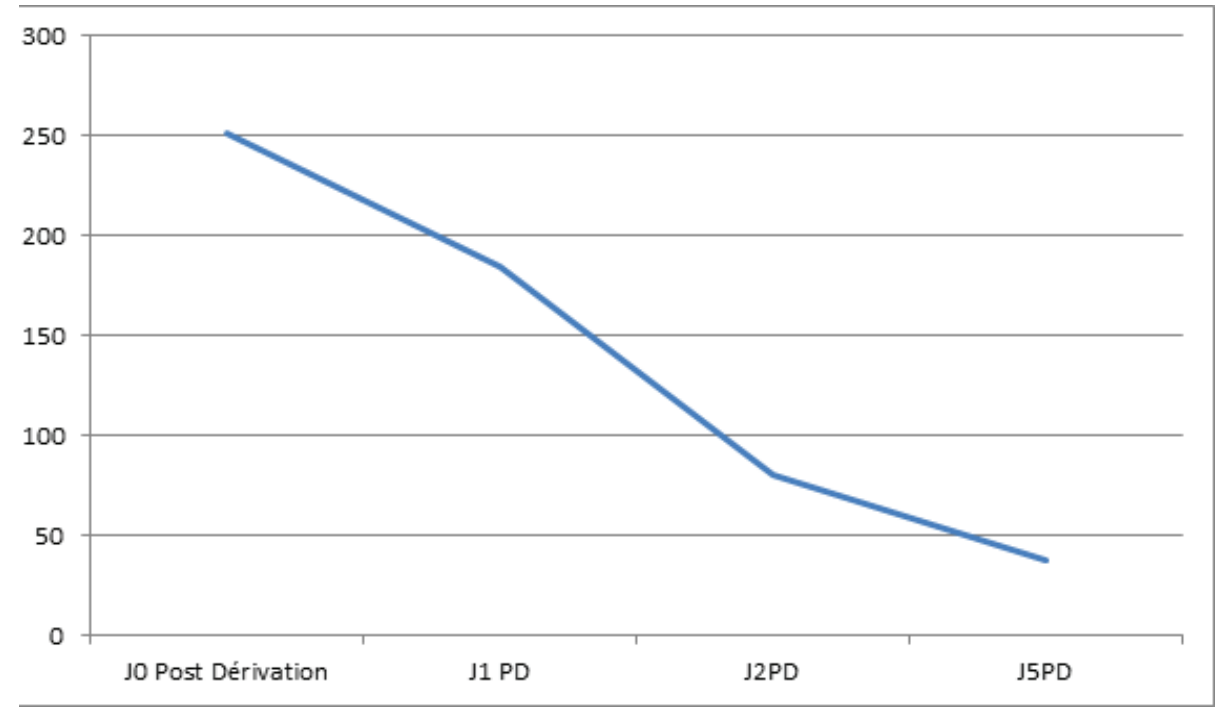

Figure 8. Evolutionary profile of the CRP after the bypass by the double J probe ascent

echogenic content (Figure 6). The MRI regained a moderate ureters hydronephrosis. Ureters hydronephrosis appearance on the right and lesser to the left associated with pyelitis with an average calicial lithiasis of $7.3 \mathrm{~mm}$ (Figure 7).

Management provided by 3rd generation (2g) cephalosporin-based probabilistic antibiotic therapy and a bypass of the upper urinary tract by a bilateral J double probe ascent. Cytobacteriological examination of urine isolated a multi-sensitive Escherichia coli. The evolution was marked by clinical and biological improvement (normalization of leukocyte and CRP figures (Figure 8) ).

\section{Discussion}

Horseshoe kidney (RFC) is one of the most common congenital abnormalities of the kidneys. it is the most common fusion abnormality. The incidence of RFC is estimated at $0.25 \%$ of the general population. There is a clear male predominance with a sex ratio of 2 [1.4]. It is also important to note the frequent association of RFC with other pathological malformations: ureteral duplicity, retrocaval ureter, pyeloureteral junction abnormality, hypospadias, and other extraurinary congenital malformations which are found in more than one-third of cases[1,4]. RFC may exist in twins, 20\% with Down syndrome cases and $60 \%$ of women with Turner syndrome [4]. The RFC may remain asymptomatic, it is discovered by chance either during a systematic check-up or during a renal trauma. Elsewhere, it can be revealed by pain on the extension of the trunk (Rovsing sign ) (5 to $10 \%$ cases) or following complications and impose surgical intervention [4].

two clinical cases were reported by RFC with acute obstructive pyelonephritis.

CFRs are exposed to infectious complications(pyelonephritis) due to abnormal ureteral evolution as a result of the abnormal kidney rotation and relatively high position of the lateral pyelo-junctions $[4,5,6]$. Urinary tract infection is found in $30 \%$ of RFC carriers [8] as well as vesicoureteral reflux, which is diagnosed in more than half of cases [7], and renal lithiasis found in 20 to $60 \%$ of cases [5]. Some studies reported an infection rate between 27 and 41\% [9.10], however, these studies were limited, the largest study included only 51 subjects [11], Je, Et Al. reported a series of 825 RFC-associated patients with an incidence of acute pyelonephritis, $0.8 \%$ of them had an average age of 28 years [5]. The Clinical status of acute pyelonephritis in the two reported cases was similar to normal kidney pyelonephritis based on the association of fever, unilateral back pain, and a positive ECBU [12]. Ultrasound makes it possible to note the kidneys sitting in the horizontal plane, with an initial difficulty in seeing the lower poles, more internal than usual. The parenchymatous isthmus is easier to see in the children in front of the vessels. If it is only a fibrous bridge, diagnosis can be more difficult. 
The main role of ultrasound is to detect dilation of pyelocalicial cavities, but its presence is not always mean with obstacles. The kidney enlargement and perineal infiltration are poorly evaluated and usually recognized. The presence of intra- or perirenal abscess can be visualized at the Doppler echocardiography, with the CT scan being the main reference examination for this diagnosis [13]. The management pathway used is the same as normal kidney pyelonephritis, however, some changes in surgical treatment are sometimes necessary before the Surgical intervention for the RFC with great interest in endoscopic and percutaneous surgery for associated complications (renal lithiasis) [14].

\section{Conclusion}

RFC is the most common malformation of the renal system. It is most often discovered during associated pathologies or complications including obstructive pyelonephritis. This complication is serious and ranges between life-threatening and non-functioning of the kidney and it is considered a diagnostic and therapeutic emergency. The clinical diagnosis was similar to pyelonephritis on a normal kidney. The therapeutic methods are identical to those of the normal kidney while taking into account the anatomo-surgical peculiarities of this malformation.

\section{References}

1. Cassell A, Mohamed J, Diop PS, et al. A Review of Rare Associations of Horseshoe Kidney: Highlight of a Rare Clinical Case of Polycystic Horseshoe Kidney, Liver Cyst, and Uterine Prolapse. EMJ Urol. 2020;8(1):22-28.

2. Ito A, Kato Y, Shiomi E, et al. Renal pelvic cancer with spleen invasion arising in horseshoe kidney; a case report. Urol Case Rep. 2017;16:123-125.

3. Nikoleishvili D, Koberidze G. Retroperitoneoscopic partial nephrectomy for a horseshoe kidney tumor. Urol Case Rep. 2017;13:31-3

4. Fekak H, Mezzour MH, Rabii R, Joual A, Bennani S. The
Rein In Pathological Cheval: Therapeutic Aspects. Prog Urol. 2004;14:485-488.

5. Je BK, Kim HK, Horn PS. Incidence and Spectrum of Renal Complications and Extrarenal Diseases and Syndromes in 380 Children and Young Adults With Horseshoe Kidney. AJR Am J Roentgenol. 2015;205(6):1306-1314.

6. Bauer SB. Anomalies of the upper urinary tract. In: Walsh PC, Retik AB, Vaughan ED, Wein AJ, eds. Campbell's urology, 8th ed. Philadelphia, PA: Saunders, 2002:1898-1906

7. Turkvatan A, Olcer T, Cumhur T. Multidetector CT urography of renal fusion anomalies. Diagn Interv Radiol 2009; 15:127-134

8. Bennani S, Touijer A, Aboutaieb R, el Mrini M, Benjelloun S. Le rein en fer à cheval pathologique. Aspects thérapeutiques [Pathological horseshoe kidney. Therapeutic aspects]. Ann Urol (Paris). 1994;28(5):254-258.

9. Strauss S, Dushnitsky T, Peer A, Manor H, Libson E, Lebensart PD. Sonographic features of horseshoe kidney: review of 34 patients. J Ultrasound Med. 2000;19:27-31.

10. Pitts WR Jr, Muecke EC. Horseshoe kidneys: a 40-year experience. J Urol 1975; 113:743-746 21.

11. Gupta M, Pandey AK, Goyal N. Horseshoe kidney: a case report. Nepal Med Coll J. 2007; 9:63-66

12. Drai J, Bessede T, Patard J-J. Management of acute pyelonephritis. Progress In Urology. 2012;22(14), 871-875.

13. JF Chateil, Brisse H, DacherJN. Ultrasound in Pediatric Urology, Journal of Radiology. 2001;82:781-800.

14. Jira H, Ameur A, Kasmaoui E, Ghadouane M, Alami M, Abbar M. Rein en fer à cheval pathologique. A propos de 13 cas [Pathologic horseshoe kidney. Report of 13 cases]. Ann Urol (Paris). 2002;36(1):22-25.

15. Basar H, Basar MM, Erbil M. The comparison of the incidence of horseshoe kidney in autopsy versus urologic patient population. Okajimas Folia AnatJpn 1999;76:137-139.

16. Kohelet D, Arbel E. A prospective search for urinary tract abnormalities in infants with isolated preauricular tags. Pediatrics. 2000;105:E6. 